\title{
A REPRESENTAÇÃO SOCIAL DA CIDADANIA ENTRE JOVENS DE UMA ESCOLA PÚBLICA NO ESTADO DO PARANÁ - BRASIL
}

\author{
João Carlos Batista Morimitsu \\ Universidade Estadual do Centro-Oeste - Unicentro, PR, Brasil \\ jcbmorimitsu@gmail.com \\ Marquiana de Freitas Vilas Boas Gomes \\ Universidade Estadual do Centro-Oeste - Unicentro, PR, Brasil \\ marquiana@gmail.com
}

\begin{abstract}
RESUMO
O trabalho aqui apresentado diz respeito a uma investigação sobre as representações sociais de cidadania em um grupo de jovens escolares matriculados em escola pública da rede estadual de ensino do Paraná. O estudo envolveu 51 jovens, entre 13 e 17 anos, os quais responderam individualmente a um questionário com questões abertas e de múltipla escolha. A pergunta central desse questionário - "O que você entende por cidadania?" gerou respostas que foram ponderadas por meio da análise de conteúdo. O trabalho mostra uma possibilidade de leitura sobre as representações sociais e como elas podem ser utilizadas para a aproximação dos jovens escolares e de seus conhecimentos. Compreende-se que a articulação entre esses dois saberes é de fundamental importância para uma educação significativa aos jovens, permitindo ainda a problematização de fenômenos por vezes naturalizados. Os resultados da pesquisa indicam que há uma representação social de cidadania específica entre os jovens, formuladas a partir da afetividade, ou seja, na relação afetiva que estabelecem na convivência coletiva na cidade, e da funcionalidade da vida em sociedade, o cumprimento de regras e leis.
\end{abstract}

Palavras-Chave: Jovens. direitos sociais. Geografia.

\section{THE SOCIAL REPRESENTATION OF CITIZENSHIP BETWEEN YOUTHS THE PUBLIC SCHOOL IN THE STATE OF PARANÁ - BRAZIL}

\begin{abstract}
This papper presented here refers to an investigation about the social representations of citizenship in a group of schoolchildren enrolled in a public school of the state network of Paraná. The study involved 51 young people, between 13 and 17, who individually answered a questionnaire with open and multiple choice questions. The central question in this questionnaire - "What do you mean by citizenship?" - generated answers that were weighed through content analysis. The work shows a possibility of reading about social representations and how they can be used to get closer to the young school children and their knowledge. We understand this approach of fundamental importance for a meaningful education for the young, allowing also the problematization of phenomena sometimes naturalized. Our conclusions indicate a social representation of specific citizenship among young people, formulated from the affectivity and functionality of life in society. These are two spheres contemplated by the young people who live in their own way, the city, and think citizenship both in an affective way with their fellow man, and in a functional way governed by rules and laws.
\end{abstract}

Keywords: Young. Social rights. Geography.

\section{INTRODUÇÃO}

A cidade é o resultado de uma produção social e histórica, onde o uso do espaço é condição básica para a existência e reprodução da vida (CARLOS et al., 2011). Em todo o mundo existem inúmeras cidades portadoras de características específicas, reflexo da sociedade que a produziu. Não existem no mundo duas cidades iguais, e, até mesmo no interior das cidades as diferenças entre seus lugares são inúmeras. Uma breve análise sobre a origem das cidades permite perceber processos de

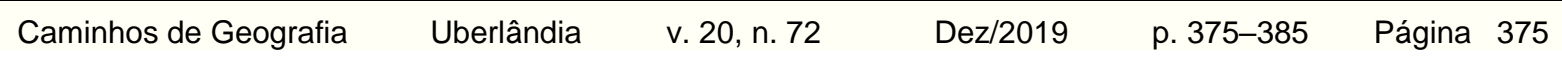


formação distintos, seja por conta do contexto histórico, seja pela natureza do sítio urbano. Consequentemente, o processo de urbanização também se fez de modo distinto.

Grande número de cidades brasileiras, a exemplo de tantas outras cidades latino-americanas, urbanizou-se de forma acelerada e descontrolada. O planejamento urbano proposto não foi adequado à realidade de grande parcela da população, isto porque em grande medida a urbanização brasileira se deu em meio aos interesses das classes dominantes (política e econômica). Nessa perspectiva, verificou-se ao longo da urbanização brasileira a formação de espaços portadores de desigualdades e deficiências urbanísticas, cuja "paisagem urbana é a expressão da "ordem" e do "caos", manifestação formal do processo de produção do espaço urbano, colocando-se no nível do imediato" (CARLOS, 1992, p. 36).

A produção do espaço em sua dimensão política e econômica cria lugares distintos que servirão diferenciadamente à sociedade, sendo que o espaço modificado é gerido por organizações sociais que têm o poder de decisão em suas mãos e pretendem se manter como tal. Assim, este espaço modificado "surge então não como resultado natural da evolução sócio-cultural da humanidade, mas como produto intencional e não-intencional de uma ordem estabelecida" (BARRIOS, 1986, p. 05). Trata-se de "uma produção da cidade que ocorre subjugada aos interesses de classes" (CANETTIERI, 2017, p. 514).

Todavia, interesses que são contrários em sociedade também moldam o espaço, uma vez que grupos de dominantes e de dominados, ora se confrontam, ora se harmonizam (ou habituam-se), para que suas intencionalidades se tornem decisões, sejam aplicadas na prática e adotadas pela sociedade. Via de regra, para que tais decisões se tornem práticas, é necessário que se tornem leis e normas, dentro de um marco jurídico, a exemplo dos planejamentos urbanos. É nesse ponto que o Estado, enquanto legítimo formulador das leis e responsável pelo ordenamento territorial, ganha especificidades na produção do espaço urbano.

Esse é um ponto bastante interessante para se analisar, afinal é a partir do marco jurídico e legal definido pelo Estado, nas diferentes escalas de atuação do poder público, que nossas práticas espaciais se inserem (ou se espera que seja assim) no espaço geográfico. Assim, por meio das leis o Estado regula a vida em sociedade. Contudo, vários autores têm alertado para as estratégias utilizadas pelo poder público, com especial atenção ao municipal, em favor de uma urbanização voltada à produção e reprodução do capital, em detrimento do bem a coletividade civil. É nesses termos que se verifica na atualidade que "a produção capitalista do espaço está vinculada diretamente a uma racionalidade prática do neoliberalismo, funcionando como uma nova razão do mundo" (DARDOT; LAVAL, 2016 apud CANETTIERI, 2017, p. 514). Em outros termos, equivale dizer que as práticas adotadas pelo Estado têm servido bem mais à reprodução do capital do que à produção de qualidade de vida ao conjunto dos cidadãos.

Como exemplo, analisando a questão habitacional em diversas partes do mundo, Rolnik (2015) escreve sobre como, no neoliberalismo, está presente a ideia de que o Estado deve se ausentar de setores em que o mercado (capital) pode realizar o controle. Uma das constatações da autora é de que a habitação, antes entendida como bem estar social passou a ser vista como mercadoria, gerando consequências desastrosas mundo a fora.

Nas palavras de Santos (2013, p. 86) "o espaço é hoje um sistema de objetos cada vez mais artificiais, povoados por sistemas de ações igualmente imbuídos de artificialidade [...]". É nesse conjunto de sistemas, de objetos e de ações, que as relações sociais se processam, tornando-se concretas, juntamente com o espaço que se (re) produz. Desse modo,

\begin{abstract}
"as relações sociais têm concretude no espaço, nos lugares onde se realiza a vida humana, envolvendo um determinado dispêndio de tempo que ressalta um modo de uso do espaço envolvendo dois planos: o individual (que se manifesta em sua plenitude no ato de habitar) e o coletivo (plano da realização da sociedade), portanto, na dialética entre o público e o privado. A noção de produção, nessa perspectiva, se abre para a noção de apropriação, que se revela em atos e situações. O uso se realiza através do corpo (que é extensão do espaço) e de todos os sentidos humanos, e a ação humana se realiza produzindo um mundo real e concreto que delimita e imprime os "rastros" da civilização" (CARLOS et al., 2011, p.41).
\end{abstract}

Assim, o espaço geográfico reflete as manifestações humanas em suas várias facetas, apresentando formas e conteúdos diversos, com características diferenciadas na medida em que a sociedade, e grupos no interior das sociedades, se individualizam com o propósito de realizar a reprodução da vida.

$\begin{array}{llllll}\text { Caminhos de Geografia } & \text { Uberlândia } & \text { v. 20, n. } 72 & \text { Dez/2019 } & \text { p. 375-385 } & \text { Página } 376\end{array}$


Sem perder de vista todas estas características que constituem a cidade capitalista, o interesse desse artigo recai especialmente sobre a juventude e o uso que ela faz da cidade. Para tanto, evoca-se o conceito de cidadania como centro da análise neste texto. Tendo como pano de fundo a afirmativa de que todo conceito e ideia em nossa mente tem uma correspondência com a realidade, busca-se compreender qual é essa correspondência entre a noção de cidadania de um grupo de jovens e suas práticas espaciais na cidade. Posto de outra maneira, o objetivo é desvendar qual é a representação social de cidadania em um grupo de jovens escolares.

As representações sociais são formas de conhecer a realidade, são ideias construídas ao longo da história e compartilhadas por um grupo social, que fazem parte do imaginário social desse grupo. Elas são constituídas também pelo conhecimento científico, que ao circular em sociedade ganha suas versões populares. Nesse sentido, pode-se dizer que o conhecimento se encontra em dois universos: o institucional que é o da academia, e o do senso comum, que orienta o conhecimento prático (MOSCOVICI, 2009). De fato, o senso comum orienta a prática no cotidiano, e é aqui que o objetivo desse texto se conecta com a teoria das representações sociais.

Essa discussão está organizada no artigo a partir da problematização sobre a relação da Geografia e a cidadania, na primeira parte; da apresentação do caminho metodológico traçado na investigação, na segunda parte; e da análise dos dados obtidos na pesquisa com os jovens escolares, na terceira e última parte.

\section{GEOGRAFIA E CIDADANIA}

Nem sempre a Geografia se ocupou, ao menos de forma direta, do tema da cidadania. A "entrada do conceito na Geografia", como escreveu Piñon de Oliveira (2011, p. 178), se deu a partir da segunda metade do século XX, marcada por uma "renovação do debate temático e teórico", guiado por transformações pelas quais o mundo passava. Na opinião desse autor, nos anos 1970, três obras surgem como possibilidades de aproximação da Geografia com a cidadania, sendo elas o livro "A justiça social e a cidade", de David Harvey, o livro de Yves Lacoste, intitulado "A Geografia - isso serve, em primeiro lugar, para fazer a guerra", e a obra "Société, espace et justice: inegalités régionales et justice socio-spatiale" de Alain Reynaud.

Outros autores também são abordados por Piñon de Oliveira (2011) para explicitar a inserção da cidadania enquanto tema de análise na Geografia. Dentre eles, o filósofo e sociólogo Henry Lefebvre apresenta grande contribuição. $\mathrm{O}$ destaque encontra-se nas suas obras "O direito à cidade" e em "Espaço e política", livros que articulam a cidade e o espaço urbano ao direito à cidade, entendendo a "política como parte constitutiva do seu próprio espaço" e capaz de modelá-lo. "Além do direito à cidade, segundo ele, ainda muito mal assimilado como nova cidadania, Lefebvre destaca seis outros direitos a serem reforçados nessa construção [da cidadania]" (PIÑON DE OLIVEIRA, 2011, p 181). Esses direitos são em relação à informação, à expressão, à cultura, à identidade na diferença, à autogestão e o direito aos serviços. Essa noção de cidadania apresentada por Lefebvre é bastante ampla, e transborda de significados o conceito, por permitir outras formas de se olhar para o indivíduo que se insere no coletivo da sociedade.

Susan Smith (1989 apud PIÑON DE OLIVEIRA, 2011) fez a relação da cidadania com o espaço e a sociedade, na busca por uma construção teórico-metodológica para Geografia Humana. Harvey (1980), de maneira indireta, tratou do tema com a abordagem sobre as novas formas de se vivenciar o tempo e o espaço por meio da contração de ambos (a contração tempo-espaço). Gomes (1997, apud PIÑON DE OLIVEIRA, 2011) propõe um mergulho no conceito de cidadania e também sua atualização, diante das transformações do mundo contemporâneo, afirmando, sobretudo, que no conceito de cidadania existe uma matriz espacial, uma vez que entende o cidadão como aquele que possui direitos e deveres que se inserem em relações inscritas no espaço.

No Brasil, o primeiro trabalho a abordar diretamente o tema da cidadania na Geografia foi a obra de Milton Santos, -"O espaço do cidadão":

De motivação mais política e conjuntural que acadêmica - no clima da redemocratização do Brasil e como contribuição ao debate da nova Constituição de 1988 - o autor apresenta alguns pontos importantes para a reflexão do problema da cidadania e suas dimensões socioeconômico-político-espaciais, entre eles: o papel da cultura e do território na conformação de um modelo cívico; a importância do componente territorial para assegurar a distribuição geral dos bens e serviços públicos; o atrofiamento da cidadania na sociedade de consumo de massas, reduzindo o cidadão a consumidor e usuário; a mutilação do cidadão pelo agravamento das desigualdades sociais em tempos de políticas neoliberais; e o direito ao entorno, à vida urbana e aos espaços públicos (praias, montanhas,

$\begin{array}{lllll}\text { Caminhos de Geografia } & \text { Uberlândia } & \text { v. 20, n. } 72 & \text { Dez/2019 } & \text { p. 375-385 Página } 377\end{array}$


calçadas etc.), que já vinham impunemente segundo ele, sendo privatizados. (PIÑON DE OLIVERIA, 2011, p. 180)

A importância do livro "O espaço do cidadão" para se compreender aspectos da realidade social brasileira é indiscutível, e mesmo após vinte anos desde sua primeira publicação, seus textos guardam estreita relação com nossa atualidade.

Outra contribuição são os escritos de Carlos et al. (2011), cuja preocupação com a cidadania levou-a a propor uma metageografia. Para a autora, como já mencionado no início desse texto, o espaço é condição para a reprodução da vida, e é a partir da produção desse espaço que a humanidade se constrói.

\begin{abstract}
O ponto de partida, já anunciado, é o entendimento da produção do espaço como momento da construção da humanidade do homem, revelando-se como espaçotempo da atividade que produz o homem e o mundo - as condições objetivas da existência humana tanto quanto a subjetividade contida na consciência que vem da e se encontra situada na prática. Uma prática que revela, drasticamente, crises e cisões vividas. Essa concepção de espaço exige o deslocamento da análise do campo da epistemologia para aquele da práxis, ou seja, o campo das condições objetivas da existência do cidadão em direção à sua realização, superando cisões e alienações como conteúdos da produção alienada do espaço. (Carlos et al., 2011, p. 147)
\end{abstract}

Assim, a autora conduz a reflexão sobre a prática cotidiana e as condições objetivas com as quais pode-se apoiar (ou não) no espaço para que tal ação se realize, sem perder de vista a necessidade de melhorar a capacidade crítica e de formulações de pensamentos acerca da cidade que se ergue nos moldes do neoliberalismo.

Carvalho (2008, p. 9), por sua vez, escreveu que "Uma cidadania plena, que combine liberdade, participação e igualdade para todos, é um ideal desenvolvido no Ocidente e talvez inatingível". Esse autor explica que para o exercício pleno da cidadania, o indivíduo deveria ser titular de direitos civis, políticos e sociais, entendendo por direitos civis àqueles que são fundamentais para a realização da vida, como a igualdade perante a lei, ou o direito de ir e vir livremente; por direitos políticos, a participação do cidadão no governo (o que efetivamente é limitado a apenas poucos, cidadãos, é ampliado para a maioria por meio do voto), e por direitos sociais tudo aquilo que garantiria uma participação nos frutos do que a coletividade produz (CARVALHO, 2008).

Essa complexidade presente no conceito de cidadania traduz seu caráter "talvez inatingível". Entende-se que os elementos indicados por Carvalho (2008) são fundamentais, além dos deveres do cidadão para com sua sociedade, conforme preconizam leis e regulamentações diversas, com destaque para a Constituição Federal do Brasil (pensando no território brasileiro). Nesse sentido, compreende-se a cidadania como o conjunto de direitos e deveres (civis, políticos e sociais) do indivíduo em sua sociedade, os quais lhes garantem participação e uso dos serviços e equipamentos ofertados pelo Estado.

A qualidade da participação de cada indivíduo na estrutura fornecida pelo Estado tem relação direta com a forma como as compreende. Quanto mais inteligível for a realidade, maior será a possibilidade de participação. Acredita-se que essa afirmação se conecta com o que Santos (1996, p. 7) escreveu em seu "Espaço do cidadão": "A cidadania, sem dúvida, se aprende". E continua

\begin{abstract}
"A cidadania pode começar por definições abstratas, cabíveis em qualquer tempo e lugar, mas para ser válida, deve poder ser reclamada. A metamorfose dessa liberdade teórica em direito positivo depende de condições concretas, como a natureza do Estado e do regime, o tipo de sociedade estabelecida e o grau de pugnacidade que vem da consciência possível dentro da sociedade civil em movimento". (SANTOS, 1996, p. 8. Grifo dos autores)
\end{abstract}

Nesse sentido, confia-se, sobretudo, que a escola tem papel fundamental para que a cidadania seja aprendida pelos jovens escolares e, quem sabe, multiplicada para outros grupos sociais. Não apenas por ser definido em Lei, mas sim porque, enquanto ambiente de aprendizagem, ela cria possibilidades para que a capacidade de reflexão dos indivíduos seja melhorada e ampliada, acerca da realidade na qual estão inseridos.

Ressalta-se ainda que a Geografia escolar tem papel preponderante dada sua potencialidade em abarcar temas e conceitos diretamente relacionados às práticas espaciais realizadas no cotidiano. Como escreveu Ribeiro (2002, p. 124), "Homens e mulheres não nascem com o conhecimento das

$\begin{array}{lllll}\text { Caminhos de Geografia } \quad \text { Uberlândia } & \text { v. 20, n. } 72 & \text { Dez/2019 } & \text { p. 375-385 Página } 378\end{array}$


leis, dos direitos e dos deveres da cidadania, o que pressupõe um longo processo de socialização e de escolarização". E muitos conteúdos presentes no arcabouço teórico da Geografia têm grande capacidade de potencializar uma aprendizagem para a cidadania, como promotor de aprendizagens significativas que levem a vivências melhoradas no/do espaço urbano.

\begin{abstract}
Reforça-se, assim, a relação entre cidade e cidadania, salientando o sentido de se pensar e de se atuar na capacitação de pessoas para viver a cidade e dela usufruir, para lutar e participar de sua gestão, para lutar pelo seu direito à cidade (Lefebvre 1991). A contribuição da geografia, nesse sentido, é relevante, na medida em que ela lida com conceitos e sistema de conceitos que esclarecem muitos dos processos de estruturação do espaço urbano, [...] (CAVALCANTI, 2013, p. 70).
\end{abstract}

Assim, quando a Geografia consegue cumprir com essa tarefa, retira o véu de naturalidade sobre "as coisas" que acontecem ao entorno e permite que novas consciências se instalem entre os indivíduos, deixando-os mais aptos a se tornarem cidadãos.

Destarte, concorda-se com Cavalcanti (1998, p. 41) quando afirma que "A escola, porém, não é a única instância de formação de concepções e práticas da cidade, habilidades básicas no exercício da cidadania", uma vez que a cidadania se constrói no cotidiano, em diferentes esferas da sociedade. Esses são os princípios que orientaram a presente investigação, cujos procedimentos metodológicos são apresentados no tópico seguinte.

\title{
OS CAMINHOS DA INVESTIGAÇÃO
}

A investigação em tela foi realizada junto a um grupo de estudantes composto por alunos e alunas de uma escola pública da rede estadual do Paraná. Por opção não será indicado o nome da instituição, apenas algumas de suas características para que o leitor tenha a possibilidade de fazer suas comparações com outras realidades.

O colégio em questão fica na zona urbana de um município de pequeno porte, na mesorregião centro-sul do estado do Paraná. A principal fonte de renda do município provém da agricultura, e muitas empresas do setor terciário também atendem à atividade agrícola. A área que circunda o colégio é composta, em sua maior parte, por residências de padrões de construção variados. Existem também alguns estabelecimentos comerciais, como padarias, mercados, oficinas mecânicas, lojas de roupas, pet shop, loja de insumos agrícolas, bares, posto de combustível e pequenos restaurantes. Em termos de equipamento público, estão localizadas nos arredores do colégio duas praças, onde os jovens, incluindo os que frequentam o colégio, se reúnem esporadicamente. Outros equipamentos públicos estão presentes em outras localidades da cidade.

O interior do colégio constitui-se de blocos térreos, nos quais se distribuem as salas de aulas, a biblioteca, o laboratório de informática, o laboratório de ciências, a sala de vídeo, sala da direção, sala da orientação pedagógica, sala dos professores e secretaria, além dos banheiros e cantina. Existe também um pátio coberto, a quadra poliesportiva e uma ampla área a céu aberto, com mesas fixas e acentos de concreto, e um espaço onde os alunos e alunas também utilizam para jogar bola.

O colégio funciona em três períodos (matutino, vespertino e noturno), possui em seu quadro 61 professores e 20 funcionários, e conta atualmente com 927 alunos matriculados em diferentes séries, desde o ensino fundamental até o ensino médio. Desse universo, 51 estudantes, entre 13 e 17 anos, se tornaram os sujeitos investigados nessa pesquisa, que teve como objetivo central compreender qual é a representação social que esses jovens escolares têm sobre a cidadania.

O instrumento selecionado para obter as informações foi o questionário, elaborado com questões abertas e fechadas. Cada estudante respondeu ao questionário de forma individual, e não houve troca de informações entre eles durante o processo de aplicação. Dado o número de respondentes, o questionário foi aplicado em dois momentos distintos: em uma sala havia 28 estudantes (sendo 19 meninas e nove meninos) e na outra sala havia 23 estudantes (sendo 13 meninas e 10 meninos).

Com a tabulação dos dados foi possível conhecer um pouco mais do cotidiano dos jovens na cidade, pois permitiram verificar quais são as práticas espaciais mais rotineiras entre esses sujeitos. Trabalhou-se com duas maneiras distintas os dados obtidos por meio do questionário..

A primeira delas diz respeito à objetividade sobre o que está sendo investigado, com o número e gênero dos respondentes, quantos desses trabalham (quatro jovens), qual o lugar mais frequentado

$\begin{array}{llllll}\text { Caminhos de Geografia } \quad \text { Uberlândia } & \text { v. 20, n. } 72 & \text { Dez/2019 } & \text { p. 375-385 } & \text { Página } 379\end{array}$


por eles (sendo a escola, o indicado por todos) e o meio comunicação mais utilizado pelos jovens (as redes sociais são o principal meio de comunicação e informação, conforme $74 \%$ deles).

A segunda maneira foi a análise qualitativa das informações, o que implica em buscar ir além da aparência. Tomando como exemplo os dados supracitados, pode-se questionar: Se, para $74 \%$ dos jovens, as redes sociais são os principais meios de comunicação e informação, que informações são estas? Ou ainda, o que esses jovens em fase escolar, entre 13 e 17 anos, estão considerando como informação? Cabe mencionar que entre as redes sociais citadas mais utilizadas por esses jovens estão o Facebook $\Theta$ e o Instagram $\AA$, empresas criadas especialmente para o entretenimento, sendo que o viés informativo fica em segundo plano. Ainda, é importante não perder de vista o fato de que pelas redes sociais circulam um número sem fim das chamadas fake news, termo utilizado para definir as informações falsas.

Nesse sentido, buscou-se pautar as análises de modo articular os dados quantitativos e qualitativos do questionário e, para esse artigo, optou-se pela reflexão sobre as respostas da questão: "O que você entende por cidadania?" de modo que, além da aproximação da realidade dos jovens, por meio de questões referentes ao seu cotidiano, o tema cidadania foi o eixo central do instrumento. Adotouse como metodologia a análise de conteúdo a qual "[...] procura conhecer aquilo que está por trás das palavras sobre as quais se debruça" BARDIN (2004, p. 38). O desenvolvimento da análise respeitou as três fases propostas por Bardin (2004): pré-análise, exploração do material e tratamento dos resultados, conforme figura 1.

A pré-análise iniciou-se com a leitura flutuante do questionário na sua forma bruta, estabelecendo um primeiro contato com o conteúdo a ser analisado. Essa leitura inicial do material, realizada de maneira bastante dispersa, vai se tornando mais precisa e concisa, à medida que temas específicos e os indicadores buscados pela análise de conteúdo vão surgindo. Ou seja, foi tomando-se ciência das ideias apresentadas pelos jovens sobre o que entendem por cidadania.

Dessa primeira leitura, foi possível definir a questão supracitada como centro para a análise, pois nela se concentra informações também presentes em outras questões do instrumento. Na metodologia, essa etapa diz respeito à seleção dos documentos e materiais a serem analisados. Esta deve ser guiada por algumas regras, obedecendo características como a exaustividade; representatividade; homogeneidade e a pertinência. Tais características dão nome ao que Bardin (2004) chamou de principais regras para a seleção do corpus a ser trabalhado com a análise de conteúdo e, cada uma delas auxiliam na demarcação do que será analisado, inserindo o conteúdo dentro de certos limites.

A regra da exaustividade é aquela que determina que todo o conteúdo referente ao tema de pesquisa deve ser englobado na análise. Como escreveu a autora, "esta regra é completada pela de não seletividade" (Bardin, 2004, p. 91). Ou seja, ao analisar todo o questionário, não se elegeu essa ou aquela questão a priori, mas sim realizou-se uma exploração geral com vistas a conhecer as informações do instrumento (ou seja, o quê o questionário informava) e, informações diretas e indiretas que em seu conjunto permitia entender a concepção dos sujeitos quanto a cidadania.

A regra da representatividade nos indica que a análise de conteúdo pode ser realizada tendo por base uma amostra, desde que esta seja representativa do universo inicial. Deve-se levar em conta, ao operar com as amostras, a diversidade do universo analisado, pois quanto maior for a diversidade, maior será a amostra, numa tentativa de abranger o maior número de elementos distintos. Neste caso, foi importante verificar em quais questões a concepção de cidadania aparecia de forma mais explícita, independente do respondente e, que, ao mesmo tempo, indicava elementos inerentes ao conceito (conforme os pressupostos teóricos já apontados neste texto). Ou seja, buscou-se verificar se as respostas tinham o mínimo de conteúdo passível de ser considerado como uma visão profunda ou elementar de cidadania.

A regra da homogeneidade, na qual os documentos selecionados para a análise "devem obedecer a critérios precisos de escolha e não apresentar demasiada singularidade fora destes critérios de escolha" (Bardin, 2004, p.91). Desse modo, os documentos são escolhidos por aquilo que eles apresentam de comum, e não por uma singularidade que destoe no corpus. A última regra diz respeito à pertinência, e informa que todo o documento e material selecionado, devem ser oriundos de uma fonte de informação adequada e que responda aos objetivos da pesquisa e da análise em andamento. No caso da pesquisa, o único documento analisado foi o questionário, portanto, essa regra foi interpretada sobre o seguinte aspecto, eleger questões, ou uma questão, passíveis de serem comparadas em virtude do seu conteúdo.

\begin{tabular}{|c|c|c|c|c|}
\hline Caminhos de Geografia & Uberlândia & v. 20, n. 72 & Dez/2019 & Página 380 \\
\hline
\end{tabular}


Figura 1 - Desenvolvimento de uma análise.

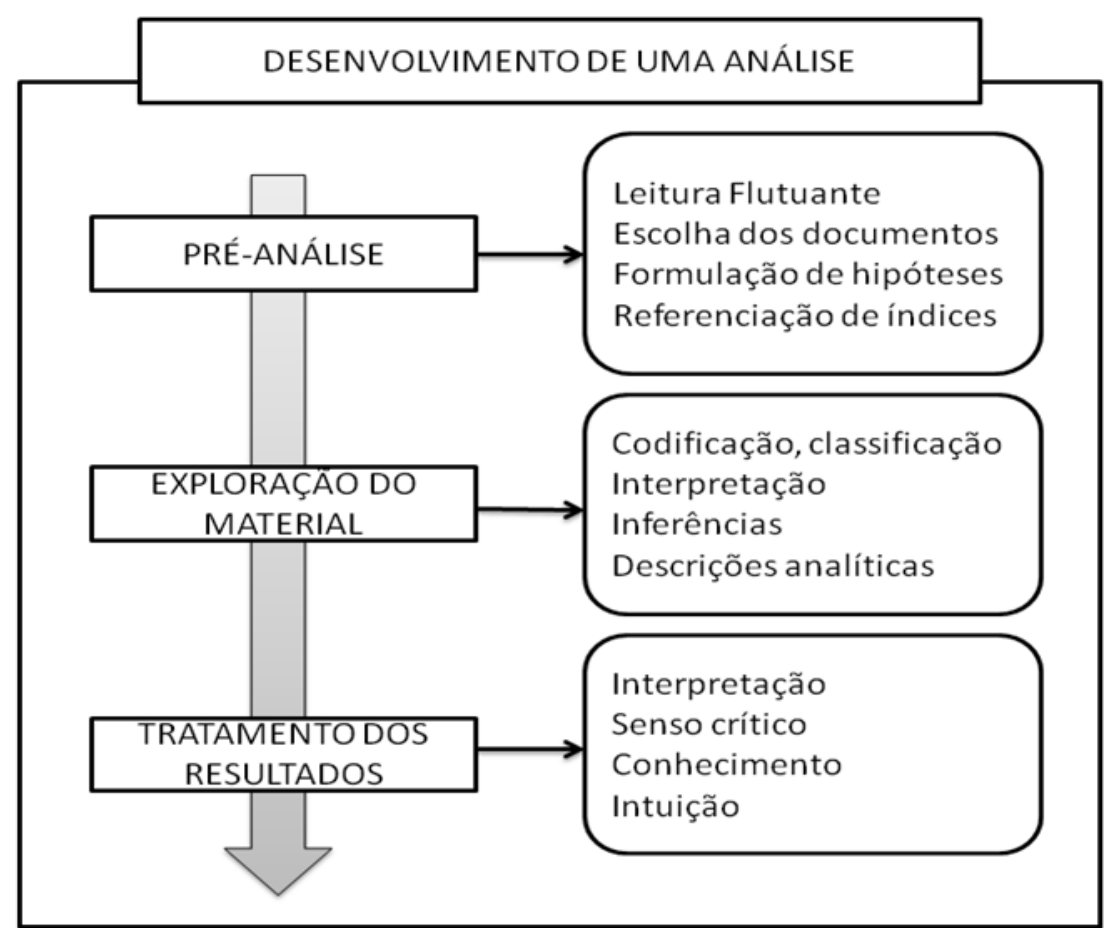

Fonte: Bardin (2004, p. 96 - Adaptado)

Org.: Autores, 2019.

O terceiro nível de abordagem, ainda no que se refere à pré-análise, é o de formulação das hipóteses e dos objetivos. Nesse momento da análise o pesquisador pode formular algumas hipóteses com base no corpus selecionado, bem como alguns objetivos a serem atingidos com a realização da pesquisa. Nesse sentido, a hipótese possível foi que os jovens têm, mesmo que de forma elementar um conceito de cidadania que orienta sua visão e ação no mundo, essa, porém nem sempre é acompanhada de uma consciência das diferentes dimensões da cidadania, mesmo em relação àqueles explícitos em marcos legais. Nesse contexto, definiu-se os seguintes objetivos: compreender quais são os elementos que integram a concepção de cidadania dos jovens e, em que medida essa tem uma implicação na sua prática socioespacial.

No quarto nível têm-se a referenciação dos índices e a elaboração de indicadores. Conforme escreveu a autora, os textos são manifestações que contém índices e, estes por sua vez, são os elementos da análise de conteúdo. Portanto, nesse nível de abordagem, o pesquisador deve estabelecer, segundo seu tema de pesquisa e de acordo com o corpus selecionado, os índices que mais lhe importa, utilizando para tanto, alguns indicadores. Os indicadores, por sua vez, podem ser caracterizados por se destacarem nos textos. Com exemplo, pode-se citar a repetição demasiada de certas palavras, ou ainda os reflexos que a emoção pode empregar nas falas, alterando a vibração da voz e a intensidade dos discursos. Partindo de algumas características como estas, o pesquisador estabelece seus índices e indicadores, organizando e sistematizando seus dados (Bardin, 2004). No caso da presente pesquisa, foram definidos dois grupos: Relações Interpessoais (RI), aquela estabelecidas entre os jovens e as demais pessoas de seu convivido no cotidiano, e Relações com o Lugar (RL), aquelas estabelecidas entre os jovens e o [ou no] lugar que frequentam. Para cada um desses dois grupos, expressões e palavras repetidas entre os respondentes foram importantes para definir o léxico inerente a cada grupo e sua relação com a visão de mundo e/ou ação no cotidiano.

Cumprida a primeira fase, chegou-se à segunda fase que consistiu na exploração do material, propriamente dito. Ou seja, é nessa fase que o pesquisador identifica as unidades de registro, aponta os elementos significantes, realiza as interpretações, as inferências e as descrições da análise. Conforme Bardin (2004, p. 95) as características que marcam essa fase são a codificação e a classificação. Ou seja, no tocante a presente pesquisa foi quando fez-se a interpretação das respostas dos jovens à luz dos dois grupos $\mathrm{RI}$ e $\mathrm{RL}$ e do referencial teórico acumulado sobre o tema Cidadania.

$\begin{array}{lllll}\text { Caminhos de Geografia } & \text { Uberlândia } & \text { v. 20, n. } 72 & \text { Dez/2019 } & \text { p. 375-385 Página } 381\end{array}$


Com isso, estabeleceu-se a interpretação dos resultados, última fase da análise de conteúdo (Bardin, 2004) que são destacados na sequência deste texto, com base na crítica apoiada na literatura sobre o tema e, não menos importante, na intuição dos autores.

\section{UMA REPRESENTAÇÃO SOCIAL DE CIDADANIA}

Como mencionado anteriormente, as respostas dadas à primeira questão central da investigação foram subdivididas em dois grupos: Relações Interpessoais (RI) e Relações com o Lugar (RL).

O núcleo de ideias que constitui o grupo das RI é composto por termos que nos remete a pensar em atitudes positivas perante a sociedade. De diferentes maneiras, os jovens responderam que entendiam cidadania como sendo uma atitude de ajuda ao próximo, ou o ato de se ter respeito pelos semelhantes e de ser respeitado também, além de considerarem a preocupação com o ambiente um ponto importante para que a cidadania se estabeleça, como podemos verificar nas citações que seguem. Cada citação apresentada foi extraída dos questionários respondidos pelos jovens, e cada um destes questionários foi identificado com a inicial $Q$, seguida de um número, visando preservar a identidade de quem respondeu, sem perder o controle dos dados.

\footnotetext{
"É você se preocupar com o próximo de um jeito bom, obedecer, ter respeito, ser um bom cidadão". (Q1)

"É se importar com as demais pessoas, com sua cidade, com o local que mora e lugares que frequenta todos os dias". (Q4)

"Respeito pelos outros e ter educação, ser gentil". (Q15)

"É se importar com as pessoas e com o ambiente" (Q11)

"É ser uma pessoa boa, que luta, corre atrás do bem, da melhora pro seu povo, pra sua cidade, ser uma pessoa de respeito e de palavra, e usa sua força pra fazer o bem, sem desejar o mal pra ninguém". (Q29)
}

A ideia de cidadania como ajudar o próximo é bastante forte entre o grupo de jovens investigados. As frases elencadas denotam uma preocupação com o outro, com o lugar que frequentam e com o ambiente. Não se trata de uma preocupação qualquer, mas uma preocupação adjetivada positivamente, como no exemplo "é você se preocupar de um jeito bom..."

O respeito também é figura central para a composição da cidadania entre estes jovens e merece atenção enquanto um valor importante a ser trabalhado entre os jovens no interior das escolas. Notamos que a ideia de respeito aparece em pelo menos três contextos diferentes. Na primeira frase, "É você se preocupar com o próximo de um jeito bom, obedecer, ter respeito, ser um bom cidadão", o respeito está junto com o contexto de obedecer.

Em outra frase, "Respeito pelos outros e ter educação, ser gentil", a aluna se refere ao respeito por outras pessoas, sua preocupação está no outro, assim como a noção de ser gentil também repousa no bem estar do outro, marcando um contexto de empatia. Mas a frase traz também a ideia de educação como componente da cidadania. A educação aqui é tratada de duas maneiras: a educação formalizada pelas instituições de ensino e a educação "trazida de casa", que permite o convívio em sociedade.

O respeito aparece também na frase do questionário 29 (Q29). Nela está presente uma ideia de contestação e de ação em direção à mudança, pois é necessário lutar, "correr atrás" de melhorias, denotando um contexto de enfrentamento da realidade. Para o autor da frase é necessário ter respeito e agir para conseguir melhorias para a coletividade.

Estas respostas, do grupo das relações interpessoais, apresentam alguns pontos em comum. De certo modo, é possível notar que as frases estão cheias de sentimentos, são carregadas de pessoalidades. As ideias de gentileza, bondade, ajuda e respeito ao próximo, inserem estas frases na esfera da afetividade. Essas ideias transmitem, por si só, outras que ajudam a formar pensamentos sobre o agir das pessoas em sociedade. Essa é uma forma de pensar e compreender a realidade por meio daquilo que se têm como cidadania.

Dessa concepção, vale destacar dois aspectos que tendem a produzir efeitos contrários. Um aspecto, a dimensão política da cidadania, no sentido da relação que o indivíduo estabelece no coletivo e que contribui para o sentimento de pertencimento, além do entendimento da condição humana que supõe igualdade de direitos, conforme destaca Carlos et.al. (2011) e Carvalho (2008). O outro, a cidadania como um atributo da personalidade humana, ser bom, preocupado, gentil e não como um direito coletivo que deve ser alcançado, vivenciado e aprendido (como afirma Ribeiro, 2002) no âmbito das

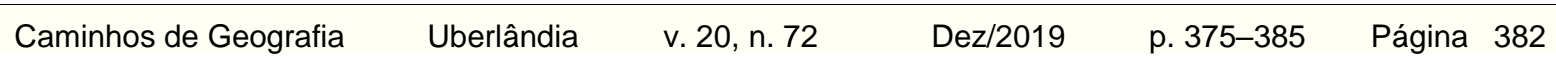


relações socioespaciais historicamente construído e transformado.. Outro conjunto de respostas deu origem ao grupo das relações com o lugar. Nesse grupo algumas das respostas também se referem ao respeito como elemento constituinte da cidadania, mas elas tratam sobre o respeito para com o lugar em que se vive. Contudo, o cerne das ideias desse grupo de respostas são as regras e os direitos do cidadão, bem como o cuidado para com o lugar que habitam. Vejamos um pouco mais das respostas dadas pelos jovens sobre o que eles/elas entendem por cidadania.

\footnotetext{
"Aquela pessoa que respeita as regras, a lei e ajuda o município e o meio ambiente". (Q9)

"É a forma que cada pessoa se compromete em meio à sociedade, é onde todos nós temos os mesmos direitos sem que alguém lhe obrigue a fazer o que não queremos, respeitando uns aos outros". (Q30)

"É ter direito pra votar, trabalhar, ter educação, ser uma pessoa do bem". (Q42)

"Várias pessoas cumprindo várias regras e leis." (Q7)

"Ajudar as pessoas, contribuir para manter a ordem no lugar onde vivemos". (Q17)
}

Notamos que esse conjunto de respostas traz outros elementos que não estavam presentes nas respostas anteriores, como o exemplo da preocupação em se cumprir as regras e se manter a ordem no lugar em que se vive. Em algumas das citações é possível perceber os olhares dos jovens sobre diferentes escalas, a exemplo do que escreveu Q9. Sua preocupação está sobre o município, mas também sobre o "meio ambiente".

O direito também foi citado em meio às definições de cidadania. Abbagnano (2007, p. 278-288) discorre sobre os significados do conceito de direito, mostrado que ele tem várias aplicações e formas de ser compreendido. Nas frases elencadas acima, a palavra direito também foi utilizada com sentidos distintos. Isso pode ser verificado no exemplo do Q30, onde a jovem escreve que "todos nós temos os mesmos direitos sem que alguém Ihe obrigue a fazer o que não queremos", e a ideia de direito se aproxima de algo que é intrínseco ao ser humano, sugerindo uma aproximação com o termo liberdade, como algo que é comum aos indivíduos. Já na frase citada em Q42 o direito é colocado como algo que foi construído em sociedade, pois ele está ligado a elementos da vida cultural de uma sociedade. Em ambos os sentidos apresentados, o direito citado pelos jovens remete à possibilidade de ação em meio à sociedade.

Para alguns, a cidadania aparece como aquilo que guia a sociedade para um bem comum, para o cuidado com o que é coletivo.

"Cidadania é quando uma sociedade se ajuda, uma pessoa a outra, para cuidarem mais do lugar onde vivem". (Q2)

"Respeito, cuidado e atenção com coisas que são coletivas e que não beneficiam só a mim". (Q13)

As ideias centrais desse grupo de respostas, das relações com o lugar (RL), indicam elementos bastante importantes para a vida em sociedade, como as regras e as leis. As frases que fazem referência tanto às regras quanto às leis, como um elemento que se liga à noção de cidadania, $e$ organiza o lugar em que vivemos, dá um sentido de funcionalidade para a cidadania. Assim, a cidadania é o respeito às regras e leis que permite o funcionamento da vida nos lugares. A funcionalidade, portanto, é outra esfera na qual a cidadania é representada pelos jovens, conforme indicou a presente análise.

Nesta concepção de cidadania o destaque é para a incorporação da dimensão cívica e social da cidadania, assim como a importância da cultura e do território como elementos constitutivos na formação do cidadão, como ensina Santos (1996). Porém, embora na dimensão cívica, apareça o cumprimento a leis e respeito às regras, e na dimensão social seja ressaltado o respeito coletivo, o cuidado com o ambiente e com lugar de vivência, chama atenção que o Estado não é evocado como uma instituição potencializadora desses direitos. Embora possa estar subentendido quando se reclama o direto a educação e ao trabalho, ainda se sobressai uma visão abstrata dos responsáveis por garantir essa cidadania. Em outras palavras, a cidadania aparece mais como um valor ou atitude, do que um direito a ser conquistado, como apresenta Carvalho (2008). A figura 2 apresenta a síntese dessa análise, incluindo as duas esferas que dão origem à cidadania.

O organograma (figura 2) revela qual é a noção de cidadania no grupo de jovens escolares pesquisados mostrando alguns dos elementos considerados importantes para a cidadania, valores que estão inseridos entre os jovens e aos quais estão familiarizados. De acordo com Moscovici (2009, p. 40), "Sempre e em todo o lugar, quando nós encontramos pessoas ou coisas e nos

\begin{tabular}{|c|c|}
\hline Caminhos de Geografia & Uberlândia \\
\hline
\end{tabular}


familiarizamos com elas, [as] representações estão presentes", e esse é um dos pontos que permite a afirmação de que entre os jovens pesquisados existe uma representação social de cidadania.

Figura 2 - Elementos que constituem a representação social de cidadania para o grupo de jovens investigados

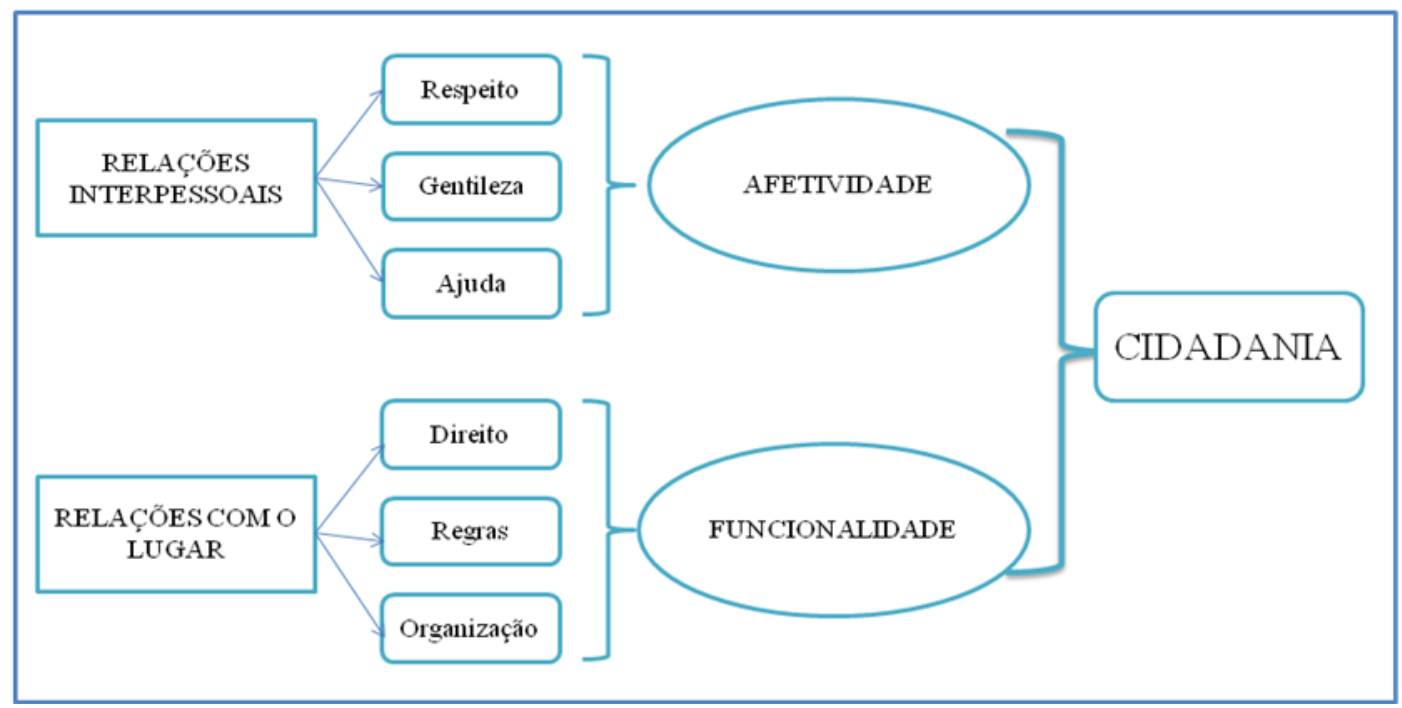

Fonte: Dados primários coletado pelos autores, 2018. Org.: Autores, 2018.

Tal representação social é concebida em meio à relação entre os indivíduos de uma sociedade, e desses indivíduos com o lugar onde habitam e frequentam. Por sua vez, estas relações são prenhes de elementos que denotam tanto a afetividade entre os sujeitos e os seus lugares, quanto à funcionalidade de um corpo social dinâmico, que se relaciona por meio de regras e leis.

\section{CONCLUSÕES}

O presente trabalho é a primeira investigação dos autores utilizando a teoria das representações sociais de Serge Moscovicie. Nesse estudo inicial foi possível compreender que as representações sociais se compõem por três elementos: a informação, o campo cognitivo e a atitude. A informação organiza o conhecimento; o campo cognitivo é onde está a capacidade de gerar imagens com respectivas cargas de conhecimentos sobre os objetos formados nessa imagem; e a atitude diz respeito ao posicionamento do sujeito frente ao objeto informado. Esse entendimento é bastante importante, pois ele nos dá pistas de como um grupo social constrói um conjunto de saberes e os utiliza em suas práticas.

Essa investigação se fez sobre um grupo social específico, os jovens escolares entre 13 e 17 anos. Tem-se como intenção apresentar as características do colégio em que tais jovens estão matriculados e frequentam, e possibilita que o leitor faça comparações com outras realidades, à medida que formula em sua mente uma ideia do lugar de onde se fala. $E$ isso faz toda a diferença, afinal, o conhecimento prático utilizado no cotidiano tem referência direta com as necessidades dos sujeitos nos diferentes lugares. Atitudes e pensamento estão relacionados. Por tal motivo, enquanto educadores, a compreensão das representações sociais de cidadania entre o grupo de jovens, pode contribuir para realizar ações que possam melhorar tanto suas reflexões quanto as atitudes deles no interior da escola.

As concepções de cidadania apresentados pelos jovens ainda estão por amadurecer. Apesar de conseguir visualizar uma representação social de cidadania no grupo investigado, as respostas formuladas se mostram cheias de ideologias, onde um sentido de justiça perpassa por tudo e todos na sociedade, como se um véu de inocência cobrisse o olhar desses jovens para a realidade que os cerca. Esse é mais um ponto que reitera a importância da escola para que a realidade seja discutida e seus problemas deixem de ser naturalizados. Destarte não se pode negar o fato de que os

$\begin{array}{lllll}\text { Caminhos de Geografia } \quad \text { Uberlândia } & \text { v. 20, n. } 72 & \text { Dez/2019 } & \text { p. 375-385 Página } 384\end{array}$


elementos indicados pelos jovens, como a gentileza, a bondade, a empatia e a ajuda ao próximo, quando inseridos nas práticas cotidianas, tornam bem melhor o espaço de convivência coletiva.

A análise de conteúdo realizada demanda uma carga significativa de criatividade sobre os dados por parte do autor, inserindo-se aí seus conhecimentos prévios sobre o assunto e sobre o universo escolar pesquisado, bem como sua própria visão de mundo. Considera-se tal aspecto de grande relevância, pois não é possível entender as palavras fora do contexto de quem as fala. Isto vale tanto para o texto que aqui apresentado, quanto para os sujeitos investigados nesta pesquisa.

\section{REFERÊNCIAS BIBLIOGRÁFICAS}

ABBAGNANO, Nicola. Dicionário de filosofia. São Paulo: Martins Fontes, 5aㅡ ed., 2007.

BARDIN, Laurence. Análise de Conteúdo. Lisboa: Edições 70, 2004.

BARRIOS, Sonia. A produção do espaço. In: SOUZA, Maria A. A.; SANTOS, Milton. A construção do espaço. São Paulo: Nobel. 1986. p. 01 - 24.CANETTIERI, Thiago. A produção capitalista do espaço e a gestão empresarial da política urbana: o caso da PBH Ativos S/A. Revista Brasileira de Estudos Urbanos e Regionais, [S.I.], v. 19, n. 3, p. 513, ago. 2017. ISSN 2317-1529. Disponível em: <http://rbeur.anpur.org.br/rbeur/article/view/5475>. Acesso em: 06 dez. 2018. https://doi.org/10.22296/2317-1529.2017v19n3p513

CARLOS, A. F. A; SOUZA, M. L de; SPOSITO, M. E. B. (Orgs.). A produção do espaço urbano: agentes e processos, escalas e desafios. São Paulo: Contexto, 2011.

CARLOS, Ana Fani Alessandri. A paisagem urbana. In: A cidade. São Paulo: Contexto, 1992, p. $35-44$.

CARVALHO, José Murilo de. Cidadania no Brasil: o longo caminho. Rio de Janeiro: Civilização brasileira, $11^{\underline{a}}$ ed., 2008.

CAVALCANTI, Lana de Souza. A cidade ensinada e a cidade vivida: encontros e reflexões no ensino de Geografia. In: 65-93, 2013. (org.). Temas da Geografia na escola básica. Campinas, SP: Papirus, $p$. 1998.

Geografia, Escola e Construção de Conhecimentos. 1. ed. Campinas/SP: Editora Papirus,

HARVEY, David. A justiça social e a cidade. São Paulo: Hucitec, 1980.

MOSCOVICI, Serge. Representações sociais: investigações em psicologia social. Petrópolis/Rio de Janeiro: Vozes, 2009.

PIÑON DE OLIVEIRA, Márcio. Para compreender o leviatã urbano - a cidadania como nexo políticoterritorial. In: CARLOS, A. F. A; SOUZA, M. L de; SPOSITO, M. E. B. (Orgs.). A produção do espaço urbano: agentes e processos, escalas e desafios. São Paulo: Contexto, 2011, p. 177 - 206.

RIBEIRO, Marlene. Educação para a cidadania: questão colocada pelos movimentos sociais. Educação e Pesquisa, São Paulo, v. 28, no 2, p. 113-128, jul./dez., 2002. Acessado em 06/12/2018. https://doi.org/10.1590/S1517-97022002000200009

ROLNIK, Raquel. Guerra dos lugares: a colonização da terra e da moradia na era das finanças. São Paulo: Boitempo, 2015.

SANTOS, M. Técnica, espaço, tempo: globalização e meio técnico-científico-informacional. São Paulo: Editora da Universidade de São Paulo, 2013.

SANTOS, Milton. O Espaço do Cidadão. São Paulo: Editora Nobel, 1996.

${ }^{i}$ Recebido em: 17/12/2018

Aceito para publicação em: 10/09/2019 